\title{
A MEDICAÇ̃̃O COMO ÚNICA RESPOSTA: UMA MIRAGEM DO CONTEMPORÂNEO
}

Joelson Tavares Rodrigues

\begin{abstract}
RESUMo. Tendo como ponto de partida as modificações ocorridas na Psiquiatria a partir da década de 1950, as quais foram posteriormente denominadas como revolução psicofarmacológica, o autor busca investigar de que forma e com que objetivo o recurso medicamentoso vem sendo utilizado na contemporaneidade. Avalia-se, ainda, o papel desempenhado pela indústria farmacêutica em semelhante contexto. Conclui-se que a medicação tanto pode ser empregada como forma de adequação a um sistema de valores previamente constituído, buscando a solução de todos os conflitos humanos através do recurso medicamentoso, como pode ser um instrumento de libertação e de mudança.
\end{abstract}

Palavras-chave: revolução psicofarmacológica, medicalização, mudança.

\section{MEDICINE AS AN UNIQUE ANSWER: A CONTEMPORANEOUS ILLUSION}

\begin{abstract}
Having as a start the changes occurred in Psychiatry, in the 50's, which were later called psychopharmacological revolution, the author aims to investigate the way and the purpose the medicine has been employed nowadays. Also, the role carried out by pharmaceutical industry in this context is analyzed. It was concluded that medicine can be employed as a way to achieve an adjustment to a system of values previously establishes, looking for a solution of all human conflicts through a medicine, or it can be an instrument of freedom and changes.
\end{abstract}

Key words: Psychopharmacological revolution, medicalization, changes.

\section{INTRODUÇÃO: A REVOLUÇÃO PSICOFARMACOLÓGICA}

Iniciamos as nossas considerações, no presente artigo, tendo como ponto de partida as modificações ocorridas no pensamento psiquiátrico a partir da década de 1950, as quais vieram a ser conhecidas, posteriormente, como a "revolução psicofarmacológica". Tais mudanças têm como figura culminante e emblemática a publicação da terceira edição do Manual de Diagnóstico e Estatística de Doenças Mentais da Associação Psiquiátrica Americana (DSM-III) (APA, 1980). Ehrenberg (1998) afirma que dois movimentos, a princípio não antagônicos, marcaram esta época: se por um lado o ano de 1952 é conhecido como o da descoberta do primeiro neuroléptico - a clorpromazina - por outro, será nas décadas de 1950/1960 e 1970 que a Psicanálise conhecerá o seu apogeu. À época a relação entre
Psiquiatria e Psicanálise era evidente e significativa. Vivia-se nos Estados Unidos, especialmente em função da influência de Adolf Meyer, a era da chamada "Psiquiatria dinâmica": os transtornos mentais eram considerados secundários à angústia, que, por sua vez, se originaria de conflitos intrapsíquicos inconscientes. Para Ehrenberg (1998), a descoberta das primeiras substâncias farmacologicamente ativas não altera tal panorama, ao contrário: “(...) a descoberta dos neurolépticos e antidepressivos suscita rapidamente um consenso: uma quimioterapia é eficaz quando combinada a uma psicoterapia. Este é o grande credo francês dos anos 1950 e 1960" (Ehrenberg, 1998, p. 26).

Tal acordo, entretanto, não se mantém. As promessas das novas medicações são cada vez mais sedutoras, pois ao invés de anos de tratamentos em um processo psicoterapêutico, as novas substâncias desenvolvidas acenam com a abolição dos sintomas em poucas semanas.

Médico Psiquiatra, Mestre em Psicologia pela UFF, doutorando de Psicologia da UFRJ, Pesquisador do Grupo de pesquisa "Filosofia e Psicologia Clínica" da UFF.

Endereço para correspondência: Rua Rua Padre Guilherme Lago Castro, 461, Cancela Preta, Cep 27937720, Macaé, RJ. E-mail: joelsonrodrigues@ hotmail.com 
Este panorama fica evidente, no final de década de 80, com o lançamento da fluoxetina, a primeira das substâncias do novo grupo de antidepressivos, os chamados ISRS - inibidores seletivos da recaptação da serotonina - teoricamente tão eficazes como os anteriores tricíclicos, os quais, no entanto, exatamente por seu caráter de seletividade no sistema de neurotransmissão serotoninérgico, demonstraram apresentar um número de efeitos colaterais e potencial de toxicidade significativamente menores. A fluoxetina vulgariza o uso de antidepressivos - a sua utilização passa a ser em tão larga escala e os seus efeitos são tão mitificados e propalados pela mídia, que ela se converte, nos Estados Unidos, na chamada "pílula da felicidade".

À medida que os recursos farmacológicos se mostram mais eficazes, as interpretações psicanalíticas vão perdendo terreno, e, muito embora ainda sejam consideradas importantes como elemento de compreensão do adoecimento psíquico, quando se trata de uma busca de resultados efetivos, a medicação não encontra nenhum rival à altura (ao menos este é o credo que se faz presente no pensamento hegemônico na Psiquiatria contemporânea). A resposta clínica às substâncias farmacológicas passa a ser importante, inclusive, na determinação dos quadros nosológicos. Isto se mostra evidente na caracterização do chamado Transtorno de Pânico, diagnóstico criado a partir dos estudos de Donald Klein, com pacientes ansiosos. Klein inicia as suas pesquisas com a imipramina em função da sua proximidade molecular com a clorpromazina, substância descoberta na Europa em dezembro de 1950, que se mostrara eficaz nas chamadas "angústias psicóticas"1. Um grupo de pacientes com um quadro de ansiedade grave, diagnosticado, genericamente, como "agorafobia", é eleito como amostra. Estes pacientes não haviam obtido nenhuma melhora com a clorpromazina, e tinham como característica que os assemelhava a ausência de sintomas psicóticos. $\mathrm{O}$ uso da imipramina levou a grande alteração do quadro e, com o progredir das pesquisas, constatou-se que aqueles que respondiam à medicação possuíam, como sintoma em comum, a presença de episódios agudos de ansiedade, o que motivou Klein a propor uma distinção entre a "ansiedade crônica" e os "ataques de pânico." Esta distinção, então, é que será incorporada ao DSM-III em 1980. Como afirma Pereira (1997), a elaboração deste diagnóstico pode ser considerada emblemática,

1 O termo angústia psicótica, neste caso, deve-se ao fato de que, sendo os quadros psicóticos compreendidos dentro da psicodinâmica psicanalítica, suas manifestações psicopatológicas eram entendidas como formas severas de apresentação da angústia. pois, pela primeira vez, uma caracterização nosológica se dava em termos puramente pragmáticos, tendo como elemento norteador principal a resposta clínica a uma determinada substância farmacológica.

As mudanças nos sistemas classificatórios não se restringem ao Transtorno de Pânico, nem se dão sempre em função de uma resposta a uma substância farmacológica; entretanto, preparam o terreno para que as entidades nosológicas "corretamente" descritas possam ser "eficazmente" tratadas. Em conformidade com este movimento, em 1980, é publicado o DSMIII, de onde são retirados praticamente todos os termos que demonstrem uma aproximação com a teoria psicanalítica. O que fica marcado na terceira edição do DSM é o esforço no sentido de que o diagnóstico dos quadros psiquiátricos não se submeta mais a uma pretensa formulação teórica ou a hipóteses etiológicas, mas que, antes disso, se busque uma caracterização descritiva e ateórica. Esta tendência é incorporada na décima edição da Classificação Internacional de Doenças (CID-10) (OMS, 1992/1993). Ehrenberg (1998, p. 158) usa a expressão "segunda revolução" (a primeira seria a psicofarmacológica), quando se refere às mudanças instauradas na Psiquiatria com a publicação do DSM-III. Em sua análise, este modelo classificatório vem tentar oferecer uma solução a um desafio constantemente presente no campo da Psiquiatria, que é a dificuldade de se chegar a um diagnóstico, tendo-se em vista a grande diversidade de correntes imperante nesta área de pensamento. Ora, enquanto permanecemos no terreno das disputas etiológicas, não haverá jamais um consenso. O DSM, então, se propõe a não colocar a etiologia em questão, restringindo-se a fazer uma descrição ateórica do fenômeno. Sua proposta é tornar-se um sistema de referência, norteador do pensamento nosológico em Psiquiatria, tendo como princípio básico a fidelidade diagnóstica. Ehrenberg (1998) chama-nos a atenção para o fato de que, ao falar de um "transtorno mental", o DSM se refere a uma síndrome - um conjunto de sinais e sintomas - que afeta uma determinada pessoa. Como os seus próprios promotores afirmam, trata-se de uma abordagem neokraepeliniana, em que as patologias são entendidas como entidades descritíveis. No entanto, ao invés de doenças, como em Kraepelin, fala-se de síndromes, abordagem que, do ponto de vista prático, faz muito pouca diferença. O que não se faz pertinente, segundo afirmação do próprio Ehrenberg (1998), é o sentido que está subjacente ao sintoma, o que poderíamos chamar de experiência singular. Abandonar a singularidade humana em beneficio da generalização não é, entretanto, um descuido do DSM-III, mas, ao contrário, o seu próprio 
objetivo. Na verdade, o DSM-III tem a sua força, exatamente, em função de abolir qualquer perspectiva singular a favor do genérico, daquilo que não pode ser visto em uma determinada pessoa em particular, mas, por ser geral, pode caracterizar-se como sintoma de "algo", fazendo assim parte de uma síndrome.

O DSM-III marca a opção tomada pela Psiquiatria de enxergar a doença como algo em si, que pode vir a acometer um determinado sujeito. Como salienta Ehrenberg (1998), esta posição significa uma reafirmação, por parte da Psiquiatria, de sua identidade médica, em que uma depressão, por exemplo, vai ser vista da mesma forma que uma pneumonia: se não há pneumônicos, mas indivíduos com pneumonia, também não deve haver deprimidos, mas sim indivíduos com depressão. A doença então não é mais compreendida como uma experiência subjetiva de um determinado indivíduo, mas sim, como uma entidade nosológica que o acomete. A experiência subjetiva, enquanto experiência singular, não pode ser mensurada ou quantificada ${ }^{2}$; ela escapa a toda possibilidade de ser trazida para o território da precisão e, por isso, é desconsiderada em favor de um conjunto de sinais e sintomas que se pretendem imutáveis e passíveis de rigorosa avaliação. A partir destes critérios, diferentes clínicos serão capazes de chegar ao mesmo diagnóstico quando entrevistarem um determinado paciente - alcança-se por este meio a tão desejada "fidelidade diagnóstica". Como afirma Ehrenberg (1998), diante de um diagnóstico "preciso," o papel do clínico passa a ser então o de escolher o tratamento adequado, seja ele farmacoterápico, cognitivo-comportamental ou psicanalítico. Dentro deste constructo, a medicação, que tivera até então um papel de certa forma coadjuvante, sendo entendida como um potencializador do tratamento considerado principal - a psicoterapia -, é colocada em primeiro plano, sendo, em muitos casos, o único tratamento proposto.

2 É possível opor-se a esta afirmação, alegando a presença de inúmeros instrumentos de avaliação dos processos subjetivos, tais como os diversos tipos de escala largamente utilizados na pesquisa psiquiátrica internacional (escala de Hamilton para depressão, por exemplo). Em nossa compreensão, no entanto, estes modos de avaliação, muito embora nos leve a diversas asseverações importantes, acaba por enquadrar a experiência subjetiva em modelos previamente constituídos, baseados em pretensas noções do que seja o normal ou o patológico. $O$ que não se faz presente é a experiência singular, o modo como, por exemplo, cada um articula o seu sofrimento com a sua história, a sua vida, os seus sentidos e significados. É importante que se deixe claro que não nos opomos a tais procedimentos avaliatórios, apenas chamamos atenção para os seus limites.
Marta Henning (2000), em um artigo intitulado Neuroquímica da Vida Cotidiana, coloca em questão o pretenso ateoricismo do DSM-III, mostrando que este sistema classificatório acaba por se constituir em um dos elementos basilares da chamada "Psiquiatria Biológica". Muito embora a história da Psiquiatria seja marcada por uma tensão constante entre diversos modelos teóricos (psicossocial, psicológico, biológico, etc), o que chama a atenção, no presente, é o progressivo abandono deste debate em favor de uma tendência crescente do discurso biológico. A época dos grandes pensadores na Psiquiatria termina; o saber só tem sentido e valor caso se adapte ao rigor da metodologia cientificista-biologicista-farmacológica. Para os psiquiatras, tal mudança não deixa de trazer alívio, à medida que permite que eles saiam do "reino da imprecisão" e se vejam na possibilidade de serem agora "médicos", se utilizando dos mesmos elementos interventores de outras especialidades, podendo finalmente prometer rapidez e eficácia. A Psiquiatria consegue finalmente a tão sonhada adequação a um "modelo científico rigoroso", nos moldes positivistas.

\section{A SUPERAÇÃO DE TODOS OS CONFLITOS: O HOMEM COMO DEUS, O CONSUMO COMO SALVAÇÃO}

Os limites da Psiquiatria biológica vão continuamente se ampliando; a cada dia o que anteriormente se considerava característica de personalidade hoje é convertido em doença - o que se assiste atualmente é a uma progressiva compreensão neuroquímica dos fenômenos psíquicos, em que todos os dias são criadas novas patologias para as quais se busca uma solução medicamentosa. Quadros como a neurose depressiva, por exemplo, em função de sua resposta à medicação, recebem um nova denominação nosológica - distimia -, e, convertidos em "transtornos", passam a ter a medicação como tratamento de eleição.

Acreditamos poder refletir sobre esta progressiva tendência da Psiquiatria de ir ao encontro de dispositivos de intervenção considerados eficazes e rápidos (e nesse sentido o modelo psicoterápico mais valorizado pelos "psiquiatras biológicos" é o cognitivo-comportamental) dentro de um contexto ainda mais amplo, que vem se traduzindo numa medicalização da vida cotidiana. Pretende-se a simplificação e o menor esforço. Hoje temos medicações para tratar ejaculação precoce, impotência, depressão, mau-humor, preguiça crônica, distraibilidade, etc. Parece não haver limites, e aqueles que ainda existem são considerados transitórios, já que serão brevemente vencidos pelas pesquisas em curso. 
O chamado Projeto Genoma vem somar-se a esta expectativa, num crescente e esperançoso desejo de controlar todas as possibilidades de males que venham a acometer o homem e, possivelmente, em um futuro próximo, garantir a "criação" de homens plenamente saudáveis, belos, inteligentes. Quem sabe o homem não pode vir a se tornar um deus?

Estas ambições, marcadamente humanistas, caracterizaram a modernidade, mas não se encontram, de forma nenhuma, extintas na contemporaneidade. Ao contrário, os avanços tecnológicos parecem cada vez mais fortalecê-las. Bauman (1997/1998) utiliza-se de uma citação de Johan Carrol, quando este pensa as mudanças culturais produzidas pelo movimento humanista, a qual consideramos bastante ilustrativa das pretensões do sujeito contemporâneo:

Sua ambição era erigir a ordem humana na terra, em que a liberdade e a felicidade prevalecessem, sem quaisquer apoios transcendentais ou sobrenaturais - uma ordem inteiramente humana...Colocar o homem no centro significava que ele devia tornar-se o ponto arquimediano em torno do qual tudo girasse...

O axioma sobre o qual a rocha humanista devia ser moldada também foi expresso por Pico Della Mirandola, em 1846, como por qualquer um: "Nós podemos tornar-nos aquilo que queremos"... Assim os antepassados humanistas exprimiram seu axioma fundamental: o homem é todopoderoso, se sua vontade for bastante forte. Pode criar-se a si próprio. Pode escolher ser corajoso, ilustre, justo, rico, influente ou não. (Bauman, 1997/1998, p. 213)

Com a derrocada das velhas religiões do passado a chamada "morte" de Deus, proclamada por Nietzsche - o homem abandonou a pretensão de uma salvação celeste, baseada na produção de um sujeito insuficiente por natureza, sempre necessitado da ajuda e intervenção divinas. Alicerçado no conhecimento dos fenômenos naturais, deslumbrado com capacidades e recursos próprios que lhe eram desconhecidos, a presença de um Deus se lhe torna dispensável. Produz-se um novo sujeito, privatizado, com enormes potencialidades psicológicas a serem desenvolvidas, em condições de obter a felicidade e a plenitude; o alcance destas possibilidades depende do esforço e da capacidade de cada um e o seu fracasso é sempre um fracasso individual - as questões coletivas nunca são tematizadas. Este sujeito, ilhado em si mesmo, como uma mônada, vê a possibilidade de realização como uma construção pessoal, independente do outro, destruindo as condições de construção de solidariedades.

Para Bauman (1997/1998), na cotidianidade, são as incertezas concentradas nesta identidade individual que irão substituir as incertezas ontológicas sobre as quais repousavam as religiões. Em sua concepção, se antes as questões humanas eram centradas em uma salvação celeste, hoje a sua angústia surge diante do receio de não ter um lugar adequado na ordem humana. Se antes sabia-se com exatidão o que significava ser homem ou ser mulher, que garantias seriam necessárias para se conservar um casamento ou um emprego, no momento em que vivemos não se pode mais estar certo de nada - as certezas são continuamente substituídas por novas verdades, novos conhecimentos, novas formas de viver o mundo e a experiência subjetiva. Vive-se a era da dúvida, do questionamento de verdades e da fragmentação; a ameaça do desemprego, por exemplo, está continuamente presente, exigindo a cada dia uma habilidade diferente para que se tenha, ao menos, alguma esperança de se manter um espaço já alcançado - exige-se a todo o instante a superação, a urgência, a excelência. A formação contínua passa a ser uma necessidade imperiosa; todos os convites são para que sejamos super-homens, criaturas sem limites e necessidades. Neste contexto, surgem os especialistas com os seus recursos técnicos, que, ao invés do homem insuficiente das religiões do passado, irão ter em mente um homem cujas capacidades são ilimitadas, cabendo a eles ou desenvolvê-las ou corrigir as disfunções que impedem a sua manifestação.

Os homens e mulheres pós-modernos realmente precisam do alquimista que possa, ou sustente que possa, transformar a incerteza de base em preciosa autosegurança, e a autoridade da aprovação (em nome do conhecimento superior ou do acesso à sabedoria fechado aos outros) é a pedra filosofal que os alquimistas se gabam de possuir. A pós-modernidade é a era dos especialistas em "identificar problemas", dos restauradores da personalidade, dos guias de casamento, dos autores dos livros de "autoafirmação": é a era do "surto de aconselhamento" (Bauman, 1997/1998, p. 221).

Os especialistas passam a ser mais um agente na constituição de subjetividades que pretendem a infinitude e a ausência de limites, e almejam alcançála através de um mergulho em "si mesmas", de um fortalecimento dos valores intimistas, e, acima de 
tudo, através de uma relação voraz com tudo o que se possa consumir, com tudo o que seja capaz de produzir prazer.

Bauman (1998/1999) afirma que vivemos em uma sociedade de consumo, em que a principal demanda imposta a seus membros é a de ocuparem o papel de consumidores, e o principal receio, o de estarem destituídos desta possibilidade. Naturalmente que o homem sempre consumiu, mas a diferença entre a sociedade atual e a que nos antecedeu é a prioridade dada ao consumo, que ocupa, na contemporaneidade, um espaço central. $\mathrm{O}$ consumidor ideal é aquele que não se mantém fiel a nenhuma marca ou produto, sempre buscando uma satisfação nova, uma experiência prazerosa ainda não vivida. Em verdade, a satisfação é a todo o tempo acenada e prometida, mas é tudo o que não se quer. Por um lado, os donos dos meios de produção não a desejam, pois da insatisfação se originam os seus lucros; por outro, o consumidor que acredita desejá-la, alcançando-a, terá finalizado a sua viagem hedonista, o que não é de fato o que ele espera. Isto porque, muito mais do que a satisfação de um determinado desejo, o que alimenta a busca do homem contemporâneo é o desejo em si, a expectativa de encontrar um "algo" novo, alguma coisa capaz de produzir estranheza aos sentidos. A "satisfação," neste contexto, significaria a morte do desejo, a ausência de sentido. A capacidade de consumir passa a ser a medida de seu próprio sucesso na ordem humana, o distintivo de sua "salvação". Tendo acesso aos bens de consumo, o homem se sente incluído, capaz, especial; afastado desta possibilidade, ele se transforma no refugo, inclui-se entre os excluídos. A natureza compulsiva desta busca desenfreada por novas sensações - pois, em verdade, muito mais do que produtos, o que o consumidor consome são sensações - é disfarçada por máximas pós-modernas como: direitos do consumidor, liberdade de escolha, que encobrem o fato de que a única opção que não lhe é dada é a de não consumir. Este personagem, produto das modelizações pós-modernas, estará sempre buscando a "experiência máxima", capaz de uma sensação de plenitude e completa satisfação; ao mesmo tempo, ao não alcançá-la, colocará sempre sob suspeita a sua própria capacidade e condição de "se entregar". Neste contexto surge espaço para os "mestres da experiência, ou de seus produtos técnicos que possam ajudar a realçar, aprofundar ou intensificar as sensações" (Bauman, 1997/1998, p. 222). Bauman ainda dirá:

A promessa da nova experiência, capaz de esmagar, de espantar o espírito ou gelar a espinha, mas sempre animadora, é o ponto a ser realçado na venda de alimentos, bebidas, carros, cosméticos, óculos, pacotes de feriado. Cada um acena com a perspectiva de "viver a fundo" sensações nunca experimentadas antes e mais intensas do que qualquer antes provada. Cada nova sensação deve ser "maior", mais irresistível do que antes, com a vertigem da experiência máxima, "total" assomando sempre no horizonte. É esperado, e aberta ou tacitamente sugerido, que, andando pela estrada do acrescentamento quantitativo da intensidade sensual, chegar-se-ia finalmente a uma penetração qualitativa - a uma experiência não exatamente mais profunda e mais agradável, mas "totalmente diferente". E nessa jornada, uma pessoa seria ajudada por bens e serviços "meta-experimentais" os que têm em vista a intensificação dos poderes e habilidades psíquicos e físicos de "receber sensações". (Bauman 1997/1998, pp. 224, 225)

\section{USOS E O DESUSOS}

Cabe-nos questionar até que ponto a prática psiquiátrica, e, mais especificamente, o uso do dispositivo medicamentoso, têm sido contaminados por esta máquina de produção subjetiva que estabelece como verdade absoluta o consumo e o prazer e que se utiliza dos recursos técnicos para alcançar estes objetivos. Poderemos pensar as mudanças ocorridas na Psiquiatria dissociadas das alterações sociais e culturais que temos vivido em nosso tempo? Para tentar responder a estas questões gostaríamos de destacar três pontos:

1. O primeiro é de que nenhuma pesquisa e nenhum clínico sério irão difundir a idéia de que uma substância farmacológica prescrita com fins terapêuticos será capaz de dar, àquele que dela se utiliza, capacidades, estados de humor ou de vontade inexistentes em sua personalidade anteriormente ao que foi considerado o "evento mórbido". Ao contrário disto, o que a medicação tem como meta é restituir a pessoa ao "estado prémórbido", ou seja, ao estado de personalidade anterior ao que foi considerado como doença. Desta forma a noção difundida de que a fluoxetina seria algo como a "pílula da felicidade" é muito mais uma produção da mídia do que uma promessa dos psicofarmacologistas, já que tal afirmação não encontra embasamento teórico que a justifique.

2. O segundo ponto é que, a despeito do que dissemos anteriormente, se nos utilizamos de uma substância farmacológica com um paciente e não 
consideramos os fatores sociais e políticos em que ele está inserido e onde muitas vezes está sendo produzido o seu processo de adoecimento, estaremos muitas vezes fazendo o papel de "ortopsiquistas"; ou seja, faremos uso da medicação meramente como um instrumento capaz de restituir aos indivíduos as possibilidades de viver plenamente as sensações, ou mesmo para prepará-lo para os estresses do cotidiano. Neste caso, o objetivo do medicamento será corrigir uma pretensa alteração relativa àquilo que consideramos a sanidade, mas não tematizaremos o que está em questão. Por exemplo, se prescrevemos um ansiolítico para uma pessoa que trabalha sob condições adversas e não refletimos sobre estas condições, privatizando desta forma o desconforto, estaremos nos colocando a serviço de uma máquina de produção capitalística ${ }^{3}$ ou, mais do que isso, sendo parte de sua engrenagem, fazendo o papel dos "mestres da experiência" da crítica de Bauman (1997/1998). As questões do trabalho são particularmente interessantes para esta reflexão, pois os ideais de trabalhador sempre pronto, disponível, capaz de dar conta de todas as demandas do sistema produtivo, são extremamente potentes na contemporaneidade, assim como uma culpabilização e uma aceitação do fracasso como uma experiência individual, quando estes objetivos não são alcançados. Dessa forma, quando nos deparamos com pacientes que se vêem incapazes de corresponder a todas as expectativas desta assim chamada "nova ordem mundial", ou que se angustiam pela incompatibilidade ou não-inclusão no sistema de consumo que anteriormente descrevemos, cabe-nos fazer mais do que meramente prescrever uma medicação como forma de propiciar um "melhor ajustamento". A medicação é um instrumento, entre outros, capaz de auxiliar o indivíduo a superar o seu sofrimento; não nos opomos, de forma nenhuma, a sua utilização. É preciso, ao mesmo tempo, no entanto, que noções como normal e patológico, ajustado ou não ajustado, sejam colocadas em questão. Isto porque, ao avaliarmos, por exemplo, a capacidade de adequação de um paciente, estaremos referenciando-o a determinados ideais de normalidade que são constituídos historicamente, não sendo uma verdade com caráter de absoluta. Retomemos o exemplo do trabalho, em que este

3 O termo capitalístico é um neologismo criado por Félix Guattari para caracterizar as produções subjetivas que ocorrem tanto nas sociedades capitalistas quanto nos países de orientação comunista. movimento fica bem claro: um dos elementos que comumente utilizamos para mensurar a melhora de um paciente é o retorno de suas capacidades laborativas; entretanto a doença pode ser, muitas vezes, engendrada a partir de uma demanda de trabalho que não reconhece as necessidades particulares daquele que nela se encontra envolvido. Em nossa experiência somos freqüentemente procurados por pacientes que se queixam de ansiedade, irritabilidade, dificuldade de ter um sono tranquiilo, fadiga, etc. Ao fazermos a história do paciente identificamos um regime de atividades que lhe exige dedicação exclusiva, disponibilidade integral, condições laborativas altamente estressoras. Diante disso, um caminho possível seria lhe dar uma medicação ansiolítica, a fim de tentar aumentar a sua capacidade de enfrentar as situações que o perturbam. Entretanto, consideramos fundamental que tematizemos a condição estressora e não meramente nos utilizemos da medicação para reconduzi-lo, o mais rapidamente possível, ao trabalho. Um outro exemplo disto, que transcende a quentão da medicação, é a angústia - engendrada eficazmente pelos meios de comunicação e pela mídia - que os pacientes apresentam em relação a seu próprio corpo, a obsessão coletiva que se vive por uma forma física perfeita. Acreditamos que cabe ao médico muito mais do que auxiliar o paciente a corresponder a estas demandas; é imperioso que se coloquem em questão esses conclames coletivos, que produzem uma sensação constante de inadequação - há sempre um algo a ser mudado, um quilo a ser perdido, uma massa muscular a ser conquistada. A não-atenção a esse ponto tem provocado um abuso, por exemplo, das cirurgias de redução de estômago para obesidade, em que cada vez mais pacientes são diagnosticados como "obesos mórbidos". Semelhante raciocínio pode ser utilizado em outras patologias e em diferentes áreas da medicina e da Psicologia.

3. O terceiro ponto é o papel desempenhado pela mídia, porém o que desejamos aqui destacar é a atuação de um tipo específico de mídia - aquela que é dirigida particularmente aos que prescrevem medicações: os médicos. Neste caso, o que observamos é uma propaganda que se afasta dos efeitos reais das substâncias farmacológicas e se aproxima muito das promessas milagrosas que acenam com a possibilidade de dar aos indivíduos as condições de viver a "experiência máxima" da expressão de Bauman (1997/1998). Para ilustrar este ponto, fazemos, a seguir, a transcrição de 
diversas propagandas publicadas em um periódico psiquiátrico $^{4}$ e disponibilizadas para a classe médica. Na maioria delas está presente um ideal de tranqüilidade, harmonia e serenidade que a medicação promete devolver, além de uma promessa de retorno à capacidade produtiva. As imagens que acompanham as propagandas são também significativas - normalmente fotos de flores ou paisagens bucólicas, que parecem falar da possibilidade de harmonização do homem com a natureza. Por outro lado, são também muito comuns cenas em família, chamando a atenção para possibilidade de a medicação produzir a reintegração familiar, a dissolução de conflitos e a adequação a um sistema de valores cujos ideais de uma família feliz ocupam papel central. Separamos as propagandas em conformidade com o potencial terapêutico das medicações (ansiolíticos, antidepressivos, hipnóticos, antipsicóticos e anticonvulsivantes) e optamos por não omitir o nome das substâncias.

\section{1- Ansiolíticos:}

Lexotan -"Equilíbrio Restabelecido, Atividade Preservada."

"Os ideais de HARMONIA e EQUILÍBRIO estão presentes em diferentes culturas, em diferentes épocas, como uma necessidade da própria natureza humana."

Tranxilene - "A dose única da tranqüilidade." "Plena atividade sem ansiedade."

Lorium - "Tomou um ansiolítico e caiu no Rio." Em uma outra página com a figura de um desfile de escolas de samba vem a seguinte inscrição: "Lorium. Ansiolítico para Pacientes Ativos."

Lorax - "Um instrumento do médico para devolver a harmonia ao paciente."

Olcadil - "Mantém ativo o homem moderno."

3.2- Antidepressivos:

Pamelor - "Dias Produtivos... Noites Repousantes e Pamelor."

Pondera - "Dá sentido à vida."

Anafranil- "Olhando o mundo sem medo."

Aurorix- "A vida começa aos 300." (dose inicial da medicação)

Psiquial- "Acima de tudo qualidade de vida."

Hipericin- "Uma luz para guiar seus pacientes."

4 O Periódico em questão, foi o Jornal Brasileiro de Psiquiatria (JBP), publicado pelo Instituto de Psiquiatria da Universidade Federal do Rio de Janeiro (IPUB/UFRJ).
Daforin - "De bem com a vida. De bem com Daforin."

Tolrest - "A alegria, da forma mais pura."

3.3- Antipsicóticos:

Leponex - "De volta à vida."

Risperdal - "Dose diária de harmonia."

3.4- Anticonvulsivantes:

Maliasin - "Controla as crises e reintegra melhor o epiléptico ao convívio social."

3.5- Estabilizadores do Humor:

Tegretol - "Equilibra e Reintegra". "Equilíbrio perfeito".

Carbolitium - "Possibilidade de retorno à vida ativa e útil." "Um momento de equilíbrio."

Litiocar - "O encontro com o equilíbrio e a harmonia."

\section{6- Hipnóticos:}

Dormonid - "Adormeceu rapidamente e acordou irreconhecível." "Dormiu bem. Acordou ótimo."

Fica evidente que as indústrias farmacêuticas não pretendem, com as suas propagandas, meramente informar sobre as características e vantagens de seus produtos; muito mais do que isso, existe a intenção de se vender a idéia de que a medicação pode restaurar o equilíbrio, dar ao indivíduo condições de ter uma vida produtiva, reintegrá-lo plenamente à sociedade, proporcionar-lhe alegria e sentido. A medicação passa, então, a ser mais um agente na constituição do sujeito sem conflitos e limites de que falávamos anteriormente, e mesmo que os médicos, para os quais estas propagandas são dirigidas, tenham conhecimento dos limites das substâncias, torna-se difícil imaginar que eles não sejam influenciados por elas. Especialmente porque, como afirma Pignarre (1999), as pesquisas realizadas com os prescritores das medicações (os médicos) chegaram à conclusão de que estes têm como principal fonte de conhecimento das propriedades farmacológicas das substâncias a própria indústria farmacêutica, através da palavra que se pretende neutra e propagadora do conhecimento científico - de seus representantes. Neste caso, recaímos no segundo ponto de que tratamos neste texto, ou seja, a ação médica passa a ser mais um coadjuvante do sistema capitalístico e o remédio seu instrumento principal.

Ao levantarmos estes questionamentos, não pretendemos fazer uma crítica ingênua ao tecnicismo que tem tomado conta de nossas vidas. Não podemos negar os enormes avanços que os recursos farmacológicos têm ocasionado, minorando o sofrimento daqueles que padecem de enfermidades 
físicas ou psíquicas. Tal atitude seria no mínimo insensata. $\mathrm{Na}$ verdade contrariaria a nossa prática, já que, como psiquiatras, diariamente fazemos uso de medicamentos com os nossos pacientes, obtendo êxito e melhora para os seus sofrimentos. No campo das doenças mentais, muitas das transformações que hoje vêm sendo conseguidas, como a desinstitucionalização de um grande número de pacientes e as reformas nos sistemas de atendimento psiquiátrico de todo o mundo, têm sido possíveis, principalmente, graças à descoberta de inúmeras substâncias farmacológicas que mudaram a face dos hospitais psiquiátricos, até então meros espaços asilares, trazendo novas esperanças a um universo enorme de pessoas, que, no passado, só tinham como recurso a eletroconvulsoterapia e os comas insulínicos. Principalmente no campo das depressões, os avanços foram tão significativos que nenhum clínico de bom senso poderia negá-los. A compreensão neuroquímica do adoecimento psíquico permitiu, além disso, que um grande número de pacientes anteriormente culpabilizados pelos seus sofrimentos fossem hoje compreendidos como pessoas que estão realmente doentes, necessitando de cuidados e solidariedade e não de censura. Retiradas do campo do mágico, do desconhecido e, muitas vezes, do sobrenatural, as patologias psiquiátricas são hoje entendidas como entidades nosológicas a serem diagnosticadas e tratadas. É impossível negarmos que a "revolução farmacológica" é, sim, um fato concreto - as mudanças ocorridas na psiquiatria a partir da década de 1950, com a descoberta dos primeiros antipsicóticos, e, posteriormente, com os primeiros antidepressivos, são de tão larga monta que nos parecem suficientemente comprovadas pelos fatos. Todos estes dados, amplamente divulgados e defendidos pelos adeptos da psicofarmacologia, não nos parecem destituídos de razão. O problema não nos parece ser, portanto, a eficácia das medicações, que, como já dissemos anteriormente, estão suficientemente estabelecidas. $\mathrm{O}$ que pretendemos ressaltar é o uso que delas fazemos, muitas vezes, como mais um instrumento de modelização subjetiva, de formatação de padrões de normalidade; são as tentativas de nos utilizarmos das medicações para constituirmos um sujeito sem conflitos, sem angústias, sem limitações. Dizendo de um modo ainda mais claro, nos parece lícito afirmar que, se é fato que as medicações tratam com eficácia os transtornos patológicos, transcende as suas possibilidades e objetivos imaginarmos que, com a sua ajuda, o homem não terá mais que lidar com angústias, sofrimentos, melancolias. A nossa oposição se refere à absolutização deste recurso, que parece ser sugerida pelas indústrias farmacêuticas, como um elemento capaz de dar conta de todos os paradoxos da existência humana.

Um outro ponto a ser ressaltado é que, muito embora, como Bauman (1997/1998) afirma, os especialistas que surgem não se baseiem, como as religiões do passado, na imagem de um sujeito condenado à insuficiência pelo pecado original, eles, mesmo que isso possa parecer contraditório, ainda têm em mente um sujeito insuficiente. Temos, de fato, um paradoxo, pois, ao mesmo tempo que se tem a pretensão de que o homem tudo possa alcançar através de seus próprios recursos, cria-se a necessidade dos especialistas e seus procedimentos técnicos, para auxiliá-lo no seu processo de superação. Fala-se todo o tempo em vencer os limites, qualidade total, superação de obstáculos, mas o que se tem produzido são sujeitos cada vez mais necessitados de cursos, manuais de auto-ajuda, métodos, dicas, técnicas contra o estresse, e - por que não dizer? - de medicações. Parece-nos, então, que recaímos na mesma questão: a formatação de sujeitos com constante necessidade de tutela e acompanhamento. Como afirma Cecília Coimbra:

\begin{abstract}
Tais discursos que se afirmam "científicos" e "neutros" produzem na família e na sociedade em geral, "verdades" dotadas de efeitos poderosíssimos. "Essas múltiplas falas dos especialistas "competentes" geram o sentimento individual e coletivo de incompetência, poderosa arma de dominação". Desta forma, no chamado "discurso da competência” os técnicos e os especialistas aparecem como os que entendem do assunto, possuem o saber, verdadeiros iluminados, detentores do conhecimento "científico", "rigoroso" e "neutro" ( Coimbra, 1995, p.37).
\end{abstract}

Na mesma linha teórica, Guattari (1999) destaca três funções da economia subjetiva capitalística, que utilizaremos para pensar, fazendo articulações com os questionamentos que estamos levantando:

1. Culpabilização - “(...) consiste em propor sempre uma imagem de referência a partir da qual colocamse questões tais como: 'quem é você?' 'você que ousa ter uma opinião, você fala em nome de quê?", (Guattari, 1999, pp, 40-41) Este é um risco sempre presente, principalmente em uma era em que o saber técnico ganha tão grande projeção. Se antes vivíamos o momento das idéias e das hipóteses, hoje estamos na Psiquiatria na era das "verdades 
científicas", e diante da verdade não há argumentos. Imaginarmos que podemos aprisionar a experiência subjetiva em uma formulação neuroquímica significa fechar o caminho para toda e qualquer construção singular. Neste universo, a única voz potente é a dos neurobiólogos e psicofarmacologistas; aos outros cabe apenas a concordância.

2. Segregação - diretamente ligado ao item anterior, à medida que se estabelecem esquemas rígidos em que são dispostos o normal e o patológico, o adequado e o inadequado, o ajustado e o desajustado, fatalmente se constroem esquemas segregativos onde irá se localizar cada um dos grupos anteriormente divididos. É bem verdade que a compreensão fisicalista que marca a Psiquiatria contemporânea permitiu, através da melhora dos sintomas, que um grande universo de pessoas fosse "reintegrado" à sociedade; no entanto, a própria noção de reintegração é, por si só, segregadora, pois, ao contrário de um entendimento do passado, que via o adoecer psíquico como uma entre outras possibilidades de expressão da subjetividade, hoje, a diferença entre o normal e o patológico é significativamente mais marcada.

3. Infantilização - "Pensam por nós, organizam por nós a produção e a vida social". (Guattari, 1999, p. 41) A experiência de uso de uma medicação e de apropriar-se de um diagnóstico pode ser extremamente infantilizadora. Muitos pacientes passam a não mais assumir responsabilidade pelos seus males, seus humores, suas vidas, porque são "deprimidos", ou têm TPM ${ }^{5}$, ou são portadores de $\mathrm{DDA}^{6}$ ou apresentam $\mathrm{TOC}^{7}$ etc. Todas estas siglas e expressões são extremamente ricas de significados. Quantos pacientes passam a justificar todos os seus fracassos ou incapacidades em função de um diagnóstico, ou pelo uso de uma medicação! Quantos outros abrem mão da possibilidade de tentar e, acreditando-se impossibilitados pelos mesmos motivos, passam a ter uma necessidade constante de tutela e de proteção, seja por parte das famílias seja por parte dos médicos! São enfraquecidos, emudecidos; passam a ser somente aquilo que os seus prognósticos e as opiniões dos especialistas dizem que podem ser.

Tensão pré-menstrual.

6 Sigla comumente usada para denominar o Transtorno do Déficit de Atenção com Hiperatividade e Impulsividade (TDAHI).

7 Transtorno obsessivo-compulsivo.

\section{CONCLUSÃO}

Acreditamos tenha ficado suficientemente claro que as reflexões aqui trazidas não pretendem se opor ao uso da medicação, nem, por outro lado, negam sua eficácia e necessidade. Ao invés disto, o nosso interesse foi nos centrarmos nas práticas de quem a utiliza. Estas práticas podem ser profundamente libertadoras, em um contexto em que a medicação é utilizada como um intercessor, porém, sem negar as variadas linhas de força que atravessam tanto a experiência da sanidade quanto a da loucura.; mas podem também ser utilizadas como produtoras de infantilização, segregação e culpabilização. Não se trata de imaginar que a Psiquiatria deva retroceder no tempo e abandonar a atual compreensão organicista, por uma compreensão psicológica ou psicanalítica. Mais do que isso, acreditamos que a Psiquiatria não pode se fechar às diversas correntes que a atravessam, que vêm de diversas direções, que não têm nomes ou categorias especiais. A Psiquiatria deve se manter sempre aberta para a riqueza da experiência humana, que não pode estar circunscrita a nenhuma compreensão, seja ela psicológica, orgânica, social ou de qualquer outro rótulo que pretendamos utilizar. Por outro lado, é importante nos mantermos sempre atentos, afinal, é inegável que a Psiquiatria não se acha imune às influências históricas, que convidam todos os saberes a se revelarem ao modo instrumental, ao modo da utilidade, da eficácia. Também ela é chamada a se colocar ao lado dos instrumentos de poder e de verdade que moldam subjetividades, constituem desejos, instituem vontades e aspirações. Nesse sentido é fundamental que, como profissionais, nos mantenhamos em constante reflexão sobre as nossas práticas.

O que tencionamos apontar são as contradições, os custos e a constante tendência a tentarmos solucionar todos os paradoxos da existência humana, tendo como projeto um sujeito plenamente realizado e sem limites. Apontamos ainda como a medicação vem sendo utilizada não somente como forma de alívio ou de cura de uma determinada síndrome, mas também como parte de um sistema que produz subjetividades privatizadas, desinvestidas de qualquer cogitação social ou política, alicerçadas na crença de uma suposta natureza humana normal, que ela promete restaurar. Embora não possamos negar os grandes avanços que as substâncias químicas têm trazido, cumpre-nos alertar para a necessidade de as utilizarmos como um instrumento político, que, ao invés de aprisionamentos, seja capaz de produzir espaços de liberdade e singularização. 


\section{REFERÊNCIAS}

American Psychiatric Association (1980). DSMIII. Diagnostic and statistical manual of mental disorders (3rd ed.). Washington, DC: Autor.

Bauman, Z. (1998). O mal-estar da pós-modernidade.(M. Gama \& C.M. Gama, Trads.) Rio de Janeiro: Jorge Zahar. (Originalmente publicado em 1997).

Bauman, Z. (1999). Globalização: as consequências humanas. (M. Penchel, Trad.) Rio de Janeiro: Jorge Zahar. (Originalmente publicado em 1998).

Coimbra, C. M. B. (1995) Guardiões da ordem. Rio de Janeiro: Oficina do Autor.

Ehrenberg, A. (1998) La fatigue d'être soi. Paris: Odile Jacob.

Guattari, F. \& Rolnik, S. (1986) Micropolítica. Cartografias do desejo. Petrópolis: Vozes.

Henning, M. (2000). Neuroquímica da vida cotidiana. Cadernos do IPUB, VI, 18, 123-132. Rio de Janeiro: UFRJ/IPUB.
Organização Mundial de Saúde. (1993). Classificação de transtornos mentais e de comportamento da CID-10. (D. Caetano, Trad.) Porto Alegre: Artes Médicas, 1993. (Originalmente publicado em 1992).

Pereira, M.E.C. (1997). Mudanças no conceito de ansiedade. Em L. A. B. Hetem \& F. G. Graeff (Orgs.), Ansiedade e transtornos de ansiedade (pp. 12-50). Rio de Janeiro: ecnEditora Científica Nacional.

Pignarre, P. (1997). Qu'est-ce qu'un médicament? Un objet étrange, entre science, marché et société. Paris: La Découverte.
Recebido em 08/11/2002 Revisado em 25/02/2003

Aceito em 30/05/2003 